\title{
First Reported Case of Respiratory Syncytial Virus Infection Causing Guillain-Barré Syndrome
}

\author{
Scott A. Helgeson, Alexander J. Heckman, Dana M. Harris \\ Department of Internal Medicine, Mayo Clinic, Jacksonville, Florida, USA
}

\section{Abstract}

Acute immune-mediated polyneuropathies are a group of illnesses that cause paralysis following an infection. We describe a case of one of these illnesses being caused by the respiratory syncytial virus (RSV). An 81-year-old female was admitted for an RSV infection. She went into respiratory failure requiring intubation and mechanical ventilation and treatment with ribavirin. When she was extubated, she had bilateral lower extremity weakness and absent reflexes. Her disease progressed rapidly to involve her diaphragm, and eventually, the family agreed to let the natural death process occur. Our case is the first reported case in which an acute immune-mediated polyneuropathy was caused from an RSV infection.

Keywords: Acute immune-mediated polyneuropathy, ribavirin, respiratory syncytial virus

\section{INTRODUCTION}

Acute immune-mediated polyneuropathies, also known as Guillain-Barre syndrome (GBS), are a group of illnesses that cause some forms of paralysis following an infection. This infection invokes an immune response that cross-reacts with peripheral nerves..$^{[1]}$ The most common cause of GBS is Campylobacter jejuni. ${ }^{[2]}$ We report a case of an elderly woman with respiratory syncytial virus (RSV) who developed GBS. To the best of our knowledge, GBS has never been reported to be preceded by an RSV infection.

\section{Case Report}

An 81-year-old female with a history of multiple myeloma currently undergoing treatment with dexamethasone and zoledronic acid, breast cancer treated 5 years prior with lumpectomy and radiation therapy now in remission, hypertension, and hypothyroidism was admitted for a 7-day history of cough, runny nose, and sore throat. She denied fever, shortness of breath, chest pain, skin rashes, abdominal pain, and diarrhea. On physical examination, the patient was tachypneic, with no pharyngeal erythema, tonsil exudates, or respiratory accessory muscle use. Lungs were clear to auscultation and no skin rashes. Laboratories were notable for a white blood cell count of $15.1 \times 10^{9} / \mathrm{L}, 95 \%$ segmented neutrophils, bicarbonate of $17 \mathrm{mmol} / \mathrm{L}$, lactate of

\begin{tabular}{|l|l|}
\hline \multicolumn{3}{c|}{ Access this article online } \\
\hline Quick Response Code: & Website: \\
& www.ijccm.org \\
& \\
\end{tabular}

$1.5 \mathrm{mmol} / \mathrm{L}$, and procalcitonin of $0.28 \mathrm{ng} / \mathrm{mL}$. Chest radiograph showed no consolidations. Computed tomography chest showed the left lower and right lower lobe small airway disease [Figure 1]. RSV polymerase chain reaction from a nasopharyngeal swab was positive. On admission, the patient required $2 \mathrm{~L}$ of oxygen by nasal cannula, but on hospital day 2 , her oxygen requirements increased and she required high-flow oxygen. Ribavirin was started at a dose of $600 \mathrm{mg}$ twice daily orally. The patient was eventually transferred to the Intensive Care Unit and intubated on hospital day 5 for respiratory distress. She was extubated 4 days later, but bilateral lower extremity weakness and absent lower extremity deep tendon reflexes were noted on physical examination. The patient also noted paresthesias of her feet. This weakness progressed, and over the course of $24 \mathrm{~h}$, her upper extremities were involved. Laboratory investigations at this time showed normal electrolytes, normal complete blood count with differential, and normal procalcitonin; alkaline phosphatase was $62 \mathrm{U} / \mathrm{L}$, alanine aminotransferase $22 \mathrm{U} / \mathrm{L}$, aspartate aminotransferase $57 \mathrm{U} / \mathrm{L}$, and creatine kinase $198 \mathrm{U} / \mathrm{L}$. A bedside lumbar puncture was attempted but was unsuccessful.

Address for correspondence: Dr. Scott A. Helgeson, Mayo Clinic, 4500 San Pablo Road, Jacksonville, Florida 32224, USA. E-mail: helgeson.scott@mayo.edu

This is an open access journal, and articles are distributed under the terms of the Creative Commons Attribution-NonCommercial-ShareAlike 4.0 License, which allows others to remix, tweak, and build upon the work non-commercially, as long as appropriate credit is given and the new creations are licensed under the identical terms.

For reprints contact: reprints@medknow.com

How to cite this article: Helgeson SA, Heckman AJ, Harris DM. First reported case of respiratory syncytial virus infection causing Guillain-Barré syndrome. Indian J Crit Care Med 2018;22:309-10. 


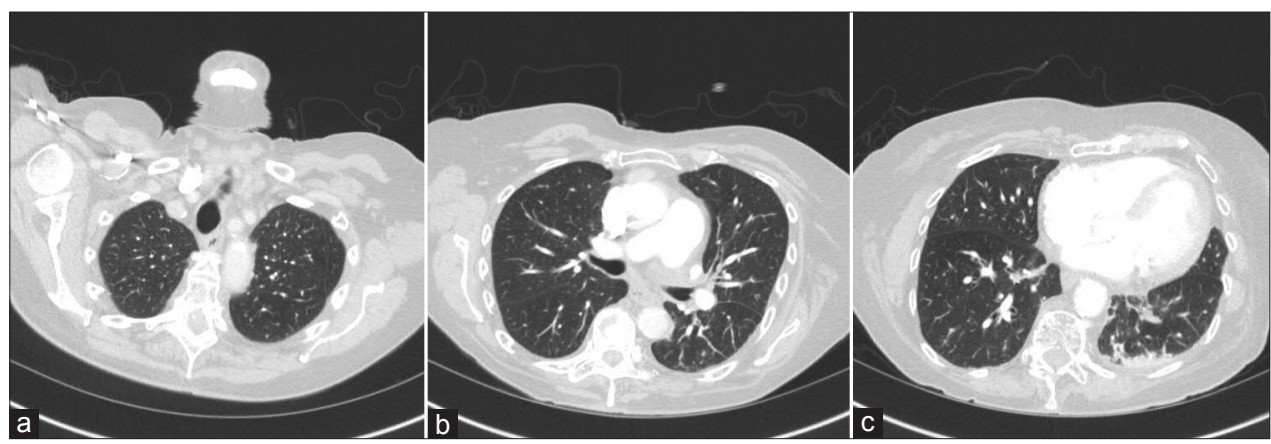

Figure 1: Initial computed tomography scan of chest with contrast of the a) apices, b) middle, and c) bases of the lungs showing multiple foci of small airway disease in the superior left and right lower lobes

Plasmapheresis was initiated, and the patient received five total of treatment with minimal improvement in quadriparesis and sensory nerve deficit. Electromyography (EMG) showed low amplitude motor responses consistent with axonal sensorimotor peripheral neuropathy. On hospital day 11, the patient's extraocular movements diminished, the gag reflex became absent, and pupil asymmetry appeared. The patient was intubated again and eventually care was withdrawn.

\section{DISCUSSION}

We present a case of GBS following respiratory infection with RSV. GBS has been reported to be caused by multiple insults with a $5 \%$ mortality rate. ${ }^{[1]}$ The most common cause is from infection, with the only reported causes being C. jejuni, HIV, varicella zoster virus, herpes simplex virus, Escherichia coli, Mycoplasma pneumoniae, Haemophilus influenzae, and the hepatitis viruses. Other causes of GBS include lymphoma, systemic lupus erythematosus, sarcoidosis, surgery, trauma, and bone marrow transplantation. ${ }^{[1,3]}$

Diagnosis of GBS is centered on the clinical presentation, with the features required for diagnosis being progressive symmetrical weakness of the legs and arms and areflexia. Other symptoms that may be present are numbness, paresthesia, facial nerve palsies, oculomotor weakness, pain, and dysautonomia. Severe respiratory muscle weakness can occur in up to $30 \%$ of patients affected by GBS, with predictors of patients requiring mechanical ventilation being older age, underlying pulmonary disease, pulmonary infections, and sepsis. ${ }^{[4]}$ Typically, an upper respiratory tract infection or diarrheal illness precludes the onset of symptoms by 3 days -6 weeks. ${ }^{[1]}$

Diagnostic tests are less useful for the diagnosis but may be used to exclude diseases mimicking GBS. A lumbar puncture helps exclude infectious or malignant causes of weakness. EMG studies are useful to determine the presence, pattern, and severity of peripheral neuropathy. ${ }^{[1]}$ The cerebrospinal fluid (CSF) may show an elevated protein level and a normal white blood cell level, but in about $50 \%$ of patients tested within the $1^{\text {st }}$ week, there is a normal CSF protein level. ${ }^{[5]}$ Supportive diagnostic features include progression of symptoms over days to weeks, relative symmetry of deficits, cranial nerve involvement, lack of fever, elevated protein in
CSF, and electromyographic abnormalities consistent with GBS.

Treatment is focused on either removing or neutralizing the antibodies responsible for the disease. Plasma exchange has been shown to reduce nerve damage and improve clinical response when it is started within the first 2 weeks of symptom onset. ${ }^{[6]}$ The typical treatment regimen is five total exchanges over at most a 2-week interval. Intravenous immunoglobulin when initiated within the first 2 weeks of symptoms has been shown to be just as effective plasma exchange at treating GBS. ${ }^{[7,8]}$ The combination of plasma exchange and immunoglobulin was studied and did not show any better than using one of those treatments alone. ${ }^{[7]}$

This case highlights the importance of physicians being aware of the clinical presentation of GBS because more common infections are starting to be reported as causing GBS.

\section{Financial support and sponsorship}

Nil.

\section{Conflicts of interest}

There are no conflicts of interest.

\section{REFERENCES}

1. Yuki N, Hartung HP. Guillain-barré syndrome. N Engl J Med 2012;366:2294-304.

2. Rees JH, Soudain SE, Gregson NA, Hughes RA. Campylobacter jejuni infection and Guillain-Barré syndrome. N Engl J Med 1995;333:1374-9.

3. Ropper AH. The Guillain-Barré syndrome. $\mathrm{N}$ Engl J Med 1992;326:1130-6.

4. Alshekhlee A, Hussain Z, Sultan B, Katirji B. Guillain-Barré syndrome: Incidence and mortality rates in US hospitals. Neurology 2008;70:1608-13.

5. Fokke C, van den Berg B, Drenthen J, Walgaard C, van Doorn PA, Jacobs BC, et al. Diagnosis of Guillain-Barré syndrome and validation of Brighton criteria. Brain 2014;137:33-43.

6. The Guillain-Barre Syndrome Study Group. Plasmapheresis and acute Guillain-Barré syndrome. Neurology 1985;35:1096-104.

7. Plasma Exchange/Sandoglobulin Guillain-Barre Syndrome Trial Group. Randomised trial of plasma exchange, intravenous immunoglobulin, and combined treatments in Guillain-Barré syndrome. Lancet 1997;349:225-30.

8. van der Meché FG, Schmitz PI. A randomized trial comparing intravenous immune globulin and plasma exchange in Guillain-Barré syndrome. Dutch Guillain-Barré study group. N Engl J Med 1992;326:1123-9. 